\title{
Risk, Incentives and Insurance : The Pure Theory of Moral Hazard - A Comment
}

\author{
by Peter Leepin *
}

Utility theory can be used in two ways : firstly to show the behaviour of man confronted with financial risks, secondly to lay down rules for decisions in situations with financial risks. The two ways are shortly called descriptive and normative.

Human behaviour in risk situations very often is not consistent. Decisions are context-dependent, that is the same financial risk, given in two different environments will often be treated differently. The same person will further sometimes show risk aversion and propensity to risk: He concludes an insurance contract and plays a game of hazard some hours later. These are some reasons which call in question the value of utility theory as a description of real behaviour of man, at least for persons not instructed in utility theory.

In contrary to that, utility theory is probably the only valuable existing tool to give rules in risk situations. Of course one is free to accept or not to accept the axioms that lead to expected utility as a measure of risk situations.

But if expected utility is to be used for risk transfer, then it must be taken in account, that insurance companies have also risk aversion. That confirms the remark of Prof. Borch, that there will always be a profit for insurance companies, at least in theory and only in the long run.

But there is another problem. The paper of Prof. Stiglitz is based on the assumption, that the indifference curves are concave if there is no Moral Hazard. Now if the utility curve is bounded from above and from below (Arrow [1970], p. 63-65), then the indifference curve may be convex. It is easy to construct such a case for a large enough damage.

That people do not always behave corresponding to the assumptions of Prof. Stiglitz can be shown by the following quotation of Prof. Stiglitz's paper: "For instance, for "small risks" individuals are approximately risk neutral. Thus, if the government is to provide medical insurance, it is important that it focuses on major medical insurance". In reality most people are non consistent in their risk behaviour and demand full cover in medical insurance. Insurance companies that would not give

* Chairman of the Board of Management, The Baloise Insurance Company Limited. 
full protection soon would be out of the market. It is perhaps possible to convince some directors of insurance companies that they should use utility theory for their decisions on risks. To achieve the same result for private persons probably is an unsoluble task. The results of Prof. Stiglitz are completely valid within the framework of his model, but only partially in reality.

\section{REFERENCE}

ARROW, K. J. [1970]: Essays in the Theory of Risk-Bearing, North-Holland, Amsterdam. 